\title{
Avaliação do Desempenho Animal e do Pasto na Mistura Aveia IAPAR 61 (Avena strigosa Schreb) e Ervilha Forrageira (Pisum arvense L.) Manejada em Diferentes Alturas
}

\section{Marcia Maria Grise ${ }^{2}$, Ulysses Cecato ${ }^{3}$, Anibal de Moraes 4 , Paulo César Carvalho Faccio ${ }^{5}$, Marco Weber do Canto ${ }^{3}$, Clóves Cabreira Jobim ${ }^{3}$, Augusto Manoel Rodrigues ${ }^{6}$}

RESUMO - O objetivo do trabalho foi avaliar o efeito de diferentes alturas $(8,9 ; 10,0 ; 11,3 ; 11,9 ; 13,4 ; 13,6 ; 14,7 ; \mathrm{e} 18,3 \mathrm{~cm})$ na mistura de aveia cv IAPAR 61 (Avena strigosa Schreb) + ervilha forrageira (Pisum arvense L.) sobre o ganho médio diário (GMD), o ganho de peso vivo (GPV/ha), número de animais.dia, composição botânica, resíduo de MS e porcentagem de solo descoberto. Utilizaram-se novilhos nelore, em pastejo, com lotações variáveis. As alturas do pasto foram mantidas usando-se o disco medidor, com ajustes de carga animal, semanalmente. O GMD variou de 0,497 a 1,017 kg/animal/dia, nas alturas de 8,9 e 18,3 cm, respectivamente, apresentando efeito linear em função do aumento da altura do pasto. Não houve efeito das alturas do pasto no GPV/ha e número de animais.dia/ha. O GPV/ha oscilou entre 127 e $356 \mathrm{~kg} / \mathrm{ha} \mathrm{a} 8,92$ e 18,3 cm do pasto, a lotação variou de 184 à 424 animais.dia/ha nas alturas de 14,7 e 10,0 cm, respectivamente. O nível de resíduo de matéria seca/ha aumentou linearmente com o incremento da altura do pasto, na pastagem avaliada pelo método de DISCO. A aveia permaneceu dominante na composição botânica do pasto representando $99,69 \%$, enquanto que a ervilha contribuiu com $0,31 \%$ da mesma. A percentagem de solo descoberto foi decrescente à medida que se aumentou a altura do pasto. Esses resultados evidenciam que resíduos de MS superior a $18 \mathrm{~cm}$ são importantes para o desempenho animal e para a produção da pastagem.

Palavras-chave: ganho médio diário, ganho de peso/ha, lotação, composição botânica, solo descoberto

\section{Evaluation of Animal Performance and of the Pasture in a Mixture of Oat (Avena strigosa Schreb Cv. IAPAR 61) and Field Pea (Pisum arvense L.) Managed in Different Sward Heights}

\begin{abstract}
The objective of the work was evaluate the effect of different sward heights $(8.9,10.0,11.3,11.9,13.4,13.6,14.7$, and $18.3 \mathrm{~cm}$ ) of a mixture of black oat cv IAPAR 61 (Avena strigosa Schreb) + field pea (Pisum arvense L.) on the average daily liveweight gain (DLG), weight gain/ha (WGP/ha), stocking rate (animals.day/ha), botanical composition, residue of dry matter and percentage of uncovered soil of the pasture. Steer nelore was used in grazing with variable stocking rate. Maintenance of the sward heights was accomplished through the use of the disk meter, with agreement for animal load, weekly. DLG ranged from .497 to $1.017 \mathrm{~kg} / \mathrm{animal} / \mathrm{day}$, at the heights of 8.9 and $18.3 \mathrm{~cm}$, respectively, presenting linear effect with the increase of the sward height. WGP/ha oscillated between 127 and $356 \mathrm{~kg} /$ ha to 8,9 and $18,3 \mathrm{~cm}$ of sward height respectively, the stocking rate having varied of 184 to 424 animals.day/ha at heights of 14.7 and $10.0 \mathrm{~cm}$ respectively, although the sward height did not affect GPV/ha and in the pasture stocking rate. The plants of field pea marked were not grazing by the animals. The DISK methodology showed that the level of dry matter residue/ha was linearly influenced as sward height increased. The oat remained dominant in the botanical composition of the pasture representing $99.69 \%$ of it, and the field pea contributing with $0.31 \%$. The percentage of discovered soil decreased as the sward height increased. These results showed that the residue of DM was higher than $18 \mathrm{~cm}$ is important on animal performance and pasture response.
\end{abstract}

Key Words: average weight gain, live weight gain, stocking rate, botanical composition, uncovered soil

\section{Introdução}

Nas regiões norte e noroeste do Paraná, os pastos subtropicais e tropicais apresentam baixa produção de forragem, no período final do outono a início da primavera, ocasionado principalmente pelo déficit hídrico. Essas regiões têm como característica a criação de bovinos em regime quase que exclusivo de pastagem de gramíneas de estação quente. A utilização de pastos anuais de estação fria, como a aveia,

\footnotetext{
${ }^{1}$ Parte da dissertação de Mestrado em Zootecnia do primeiro autor - Universidade Estadual de Maringá -UEM.

${ }^{2}$ Engenheira-Agrônoma, Estudante de Mestrado, UEM.

${ }^{3}$ Professor do Departamento de Zootecnia da Universidade Estadual de Maringá - Av. Colombo, 5790, 87020-900, Maringá - PR Pesquisador do CNPq. E.mail: ucecato@uem.br

${ }^{4}$ Professor Dr. Departamento de Fitotecnia Universidade Federal do Paraná - Curitiba - PR.

5 Professor Dr. Departamento de Fitotecnia e Plantas Forrageiras da UFRGS-RS.

${ }^{6}$ Acadêmico do curso de Zootecia da UEM.
} 
é uma alternativa que pode ser usada para que os animais criados a pasto obtenham bons ganhos de peso por animal. Nos estudos realizados por Canto et al. (1997) e Lesama (1997), concluiu-se que pastos de inverno de gramíneas consorciadas com leguminosas apresentam altos rendimentos de forragem e altos ganhos de peso vivo por unidade de área, bem como elevados ganhos de peso por animal.

O uso de uma mistura de gramínea e leguminosa de inverno constitui-se em alternativa importante à produção animal neste período, pelos bons rendimentos e qualidade de forragem destas espécies, proporcionando altas produções por área, durante o período crítico de produção. Isto foi comprovado por Lesama (1997), em pastos consorciados de inverno, que encontrou teores de proteína bruta de 12,9 a $14,0 \%$, DIVMO de 58,9 a $63,9 \%$ e obteve ganhos de 0,928 a $1,091 \mathrm{~kg} / \mathrm{animal} / \mathrm{dia}$ e 516 a $720 \mathrm{~kg} / \mathrm{ha}$ de peso vivo, durante três meses.

O manejo conduzido em relação à altura do pasto, tem sido usado principalmente em pastagens de azevém perene e trevo branco nas condições do Reino Unido e da Nova Zelândia, sendo um parâmetro válido por estar diretamente relacionado com os níveis de resíduo MS e consumo dos animais (Bortolo, 1999). Webby \& Pengelly (1986), trabalhando com azevém perene (Lolium multiflorum L.) consorciado com trevo branco (Trifolium repens L.), constataram que a altura do pasto constitui um bom indicador do nível residual de matéria seca de forragem. Bortolo (1999), estudando a espécie Coastcross (Cynodon dactylon L (Pers) cv. Coastcross), constatou que a altura das plantas apresentou relação linear positiva com aumento dos resíduos de matéria seca, e negativa às datas de coleta.

O resíduo remanescente durante o pastejo exerce importante efeito na composição botânica, promovendo mudanças na estrutura do pasto, determinando a participação dos componentes: folha, colmo e material morto, alterando, assim, a qualidade de forragem disponível para os animais (Canto, 1994). Já a composição botânica da pastagem é importante, pelo fato de que os animais, quando submetidos à grande oferta de forragem, podem exercer maior seleção de uma espécie em relação à outra.

Ao trabalhar-se com alturas de pastos, condicionando diferentes níveis de resíduo, pode-se interferir na presença de área de solo descoberto. Segundo Moraes (1991), pode ocorrer maior adensamento do solo e riscos de erosão em decorrên- cia da falta de cobertura vegetal, que é indispensável à proteção do solo. Bortolo (1999), em experimento de pastejo, verificou uma relação positiva entre o aumento da área de solo descoberto e a redução da altura do resíduo de matéria seca.

O ganho médio diário (GMD) é um importante instrumento para ordenar as potencialidades de transformação de diferentes pastos em produto animal, visando a uma maior uniformidade de produção animal, ao longo do ano, em sistemas de produção animal baseados em pastos (Quadros \& Maraschin, 1987; Restle et al., 1993). Porém, tanto o valor nutritivo como a taxa de consumo do pasto são afetados pela pressão de pastejo (PP), que influencia o GMD por animal e o GPV/ha.

Na região sul do Brasil, Quadros \& Maraschin (1987) avaliaram as misturas de estação fria, dentre elas a aveia (Avena strigosa Schreb) + azevém (Lolium multiflorum L.) + trevo vesiculoso (Trifolium vesiculosum Savi) e foram obtidos GMD de $0,705 \mathrm{~kg} /$ animal/dia e rendimento de $495 \mathrm{~kg} / \mathrm{ha}$ de peso vivo, respectivamente. Em trabalho semelhante, Coelho et al. (1994) encontraram em pasto de aveia preta + azevém + trevo vesiculoso e aveia preta + azevém + ervilhaca rendimentos de 0,714 e $0,558 \mathrm{~kg} / \mathrm{animal} / \mathrm{dia}$ e 316 e $226 \mathrm{~kg} / \mathrm{ha}$, respectivamente.

O objetivo deste trabalho foi avaliar a composição botânica, resíduo de MS, porcentagem de solo descoberto, ganho médio diário (GMD), ganho de peso vivo por área (GPV/ha) e a lotação da pastagem de aveia preta IAPAR 61(Avena strigosa Schereb) + ervilha forrageira (Pisum arvense L.), quando manejada a alturas distintas.

\section{Material e Métodos}

O experimento foi conduzido no Noroeste do Paraná. Esta região situa-se a $23^{\circ} 25^{\prime}$ de latitude Sul, $51^{\circ} 55^{\prime}$ de longitude Oeste e 554,9 m de altitude. O clima é classificado como subtropical úmido, mesotérmico com verões quentes, geadas pouco freqüentes, com tendência de concentração das chuvas nos meses de verão (Cfa) (Correa, 1996). O solo, em que se realizou o experimento foi Arenito Caiuá, caracterizado como Podzólico Vermelho Amarelo Distrófico, de composição química: $\mathrm{pH}\left(\mathrm{CaCl}^{2}\right)=$ 4,$53 ; \mathrm{Al}^{+3}\left(\mathrm{cmolc} / \mathrm{dm}^{3}\right)=0,24 ; \mathrm{H}+\mathrm{Al}\left(\mathrm{cmolc} / \mathrm{dm}^{3}\right)=$ 4,$17 ; \mathrm{Ca}^{+2+} \mathrm{Mg}^{+2}\left(\mathrm{cmolc} / \mathrm{dm}^{3}\right)=2,22 ; \mathrm{Ca}^{+2}\left(\mathrm{cmol}^{2} \mathrm{c} / \mathrm{dm}^{3}\right)$ $=1,42 ; \mathrm{K}^{+2}\left(\mathrm{cmol}^{2} / \mathrm{dm}^{3}\right)=0,15 ; \mathrm{P}\left(\mathrm{mg} / \mathrm{dm}^{3}\right)=7,18$; $\mathrm{C}\left(\mathrm{g} / \mathrm{dm}^{3}\right)=9,23 ; \mathrm{V}(\%)=37,99$.

R. Bras. Zootec., v.31, n.3, p.1085-1091, 2002 
A área experimental, inicialmente de pastos degradados, foi utilizada com a sucessão de culturas: soja (verão 97), aveia + ervilhaca (inverno 97) e milho (verão 98), constituía-se de 6,4 hectares, divididos em oito piquetes, com área de 0,8 ha cada, e mais dois piquetes adicionais adjacentes para mantença dos animais reguladores. Os piquetes foram separados por cerca elétrica com dois fios, e possibilitavam acesso dos animais para os cochos de sal e água.

A adubação de base foi realizada usando-se $230 \mathrm{~kg} / \mathrm{ha}$ da formulação 8:30:20 (NPK), mais $16 \mathrm{~kg} /$ ha de $\mathrm{N}$ aplicado, a lanço, logo após o plantio e em seguida $50 \mathrm{~kg} / \mathrm{ha}$ de $\mathrm{N}$, na forma de uréia, 30 dias após o plantio. O pasto foi estabelecido pelo plantio direto na palha, utilizando-se $40 \mathrm{~kg} / \mathrm{ha}$ de cada espécie, em maio, cinco dias após a dessecação dos restos da cultura anterior com o produto químico glyphosate (1,5 kg i.a./ha).

O experimento constituiu-se de quatro tratamentos envolvendo alturas de pastejo, que foram monitoradas com o uso de um disco medidor (Bransby et al., 1977). Para ajustes da carga animal, semanalmente, foram realizadas 3 calibrações deste, obtendo-se uma equação de regressão entre a altura do disco e o resíduo de matéria seca naquele momento. Os tratamentos, altura do pasto, previstos inicialmente foram $4,8,12$ e $16 \mathrm{~cm}$, porém as alturas estimadas durante o pastejo foram: 8,$9 ; 10,0 ; 11,3 ; 11,9 ; 13,4$; 13,$6 ; 14,7$; e $18,3 \mathrm{~cm}$. Para manutenção destas, utilizou-se bovinos machos da raça Nelore, pesando entre $130 \mathrm{~kg}$ e $180 \mathrm{~kg}$.

Para as avaliações utilizaram-se o pastejo com lotação contínua, usando-se a técnica dos animais reguladores descrita por Mott \& Lucas (1952). Foram usados três animais "testers" que permaneceram fixos por piquete, e animais reguladores que eram manejados, entrando e saindo dos piquetes, de maneira a manter as alturas desejadas. A estimativa de MS foi realizada por intermédio do método do disco, conforme Gardner (1968). Para estimar a porcentagem de solo descoberto, utilizou-se a metodologia BOTANAL (Costa \& Gardner, 1984).

A avaliação da preferência de consumo pelos animais por aveia ou ervilha, durante o período de pastejo, foi realizada demarcando-se quatro linhas transectas, em uma repetição de cada tratamento (4 piquetes). Em cada linha foram marcados cinco perfilhos de aveia e cinco de ervilha forrageira, com anéis plásticos, sendo que foram avaliados duas vezes por semana.

R. Bras. Zootec., v.31, n.3, p.1085-1091, 2002
O desempenho animal foi avaliado por meio do controle de peso do mesmo, sendo que cada animal foi pesado no início $(02 / 07 / 98)$ e no final do período experimental (18/08/98 para os reguladores e 01/09/98 para os testers), após um período de jejum de 16 horas.

O ganho médio diário dos animais, foi estimado utilizando-se o peso final subtraído do peso inicial de cada animal, sendo este valor dividido pelo número de dias que cada animal permaneceu na unidade experimental. O número de animais.dia/ha foi estimado multiplicando-se o número de animais de cada piquete pelo número de dias que estes permaneceram no piquete, dividido pela área dos mesmos. $\mathrm{O}$ ganho de peso vivo por unidade de área (GPV/ha) foi calculado pelo produto do número de animais.dia/ ha e ganho médio diário dos animais testers (Petersen \& Lucas, 1968).

As análises estatísticas foram realizadas utilizando-se duas metodologias: a primeira delas foi utilizada para as variáveis: \% de cada espécie na composição botânica e \% de solo descoberto, neste caso as variáveis foram analisadas utilizando-se modelos lineares generalizados, empregando-se o software GLIM 4.0, admitindo-se que os dados apresentem distribuição binomial, utilizando-se uma função de ligação logística. A segunda metodologia usada foi análise de variância seguida de análise de regressão, quando cabível, por meio do programa SAEG (Euclydes, 1983), para as demais variáveis.

Foi utilizado um delineamento experimental inteiramente casualizado, com duas repetições. O modelo estatístico para análise dos resultados nos animais foi:

$$
\mathrm{Y}_{\mathrm{ij}}=\mu+\mathrm{b}_{1} \mathrm{~A}_{\mathrm{i}}+\mathrm{b}_{2} \mathrm{Ai}_{2}+\mathrm{e}_{\mathrm{ij}}
$$

em que: $\mathrm{Y}_{\mathrm{ijk}}=$ valor observado das variáveis estudadas, no piquete $\mathrm{j}$, recebendo tratamento $\mathrm{i} ; \mu=$ constante geral; $A=$ altura do pasto $b_{1}=$ coeficiente linear de regressão da variável y em função altura pastagem; $\mathrm{b}_{2}=$ coeficiente quadrático de regressão da variável y em função altura pastagem; $\mathrm{e}_{\mathrm{ij}}=$ erro aleatório associado a cada observação $Y_{i j}$.

$\mathrm{O}$ modelo estatístico para análise dos resultados no pasto foi:

$Y_{i j k}=\mu+b_{1} A_{i}+b_{2} A i_{2}+b_{3} T_{j}+b_{4} T_{2}+b_{5} A T_{i j}+e_{i j k}$ em que: $\mathrm{Y}_{\mathrm{ij}}=$ valor observado das variáveis, no piquete $\mathrm{j}$, recebendo tratamento $\mathrm{i} ; \mu=$ constante geral; $\mathrm{A}=$ altura do pasto $\mathrm{T}=$ efeito do tempo de ciclo de vida da planta; $b_{1}=$ coeficiente linear de regressão da variável $y$, em função altura pastagem; $b_{2}=$ coeficiente quadrático de regressão da variável $\mathrm{y}$, em função 
altura pastagem; $b_{3}=$ coeficiente linear de regressão da variável y em função do tempo; $b_{4}=$ coeficiente quadrático de regressão da variável y em função do tempo; $b_{5}=$ coeficiente da variável y em função da interação entre altura e tempo; $\mathrm{e}_{\mathrm{ijk}}=$ erro aleatório associado a cada observação $\mathrm{Y}_{\mathrm{ijk}}$.

\section{Resultados e Discussão}

Para permitir os ajustes da carga animal, foi feita a estimativa do resíduo médio de MS, por intermédio do disco medidor. A relação entre a altura do pasto e o resíduo de MS foi linear positiva de acordo com a Figura 1. De tal maneira que com o aumento da altura do pasto ocorreu incremento no resíduo médio de MS, mostrando que diferentes alturas condicionam diferentes resíduos de MS disponível na forragem. Esta relação é concordante com aquela encontrada por Bortolo (1999), trabalhando com a grama Coastcross. Resultados semelhantes foram observados por Penning et al. (1991) e Canto (1994), em pasto de azevém + trevo branco, onde este último obteve relação linear positiva entre a altura e o resíduo de MS, quando o pasto foi submetido aos níveis de resíduos de forragem.

A relação entre a variável porcentagem de solo descoberto (SD \%) e altura do pasto é mostrada na Figura 2. A porcentagem de solo descoberto decresceu

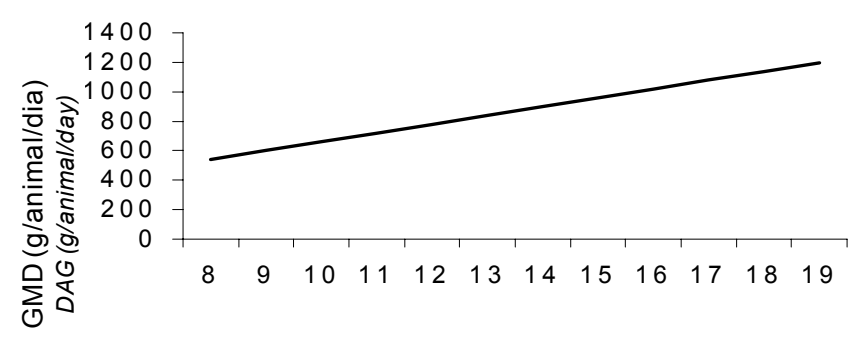

Altura do disco $(\mathrm{cm})$ Disk height $(\mathrm{cm})$

Figura 1 - Resíduo de matéria seca (kg/ha de MS) em aveia preta IAPAR 61 + ervilha forrageira, em função da altura do pasto usando a técnica do disco medidor $(\mathrm{cm}) . \mathrm{Y}=292,60+89,15 \mathrm{~A}$ $\mathrm{P}<0,05 \mathrm{R}^{2}=0,98$.

Figure 1 - Dry matter residue ( $\mathrm{kg} / \mathrm{ha} M S)$ in a mixture of oat IAPAR 61 + field pea, according to sward height using disk technique $(\mathrm{cm})$.
$(\mathrm{P}>0,05)$, à medida que aumentou a altura do pasto, sendo esta tendência também observada por Canto (1994), que ao avaliar uma mistura de azevém + trevo branco submetida a níveis de resíduos de forragem, também obteve queda linear na porcentagem de solo descoberto, à medida que se aumentou a quantidade de forragem presente na pastagem. Resultados semelhantes foram encontrados por Bortolo (1999), havendo aumento na porcentagem de solo descoberto com o incremento na altura da Coastcross.

A porcentagem de solo descoberto oscilou entre 4\% de solo descoberto (SD) na altura de $11,9 \mathrm{~cm}$, no início do período experimental, e $32 \%$ de SDnaaltura de $10,0 \mathrm{~cm}$, no final do período. Moraes (1991), que também obteve relação semelhante, ainda chama a atenção para o fato de que em condições de baixas alturas, onde o solo descoberto supera os $10 \%$, há perdas de área de pasto. Uma boa cobertura de solo permite a interceptação da água da chuva, reduzindo os riscos de erosão. O manejo do pastejo deve ser direcionado no sentido de se reduzir a proporção de solo descoberto, principalmente em solo Arenito Caiuá, devido ao impacto potencial que áreas sem cobertura vegetal podem ter sobre a degradação física deste solo.

Os GMD oscilaram de $0,497 \mathrm{~kg} /$ animal $/$ dia na altura de $8,9 \mathrm{~cm}$ a $1,017 \mathrm{~kg} /$ animal $/$ dia na altura de $18,3 \mathrm{~cm}$, apresentando comportamento linear, em função do aumento da altura do pasto, conforme se

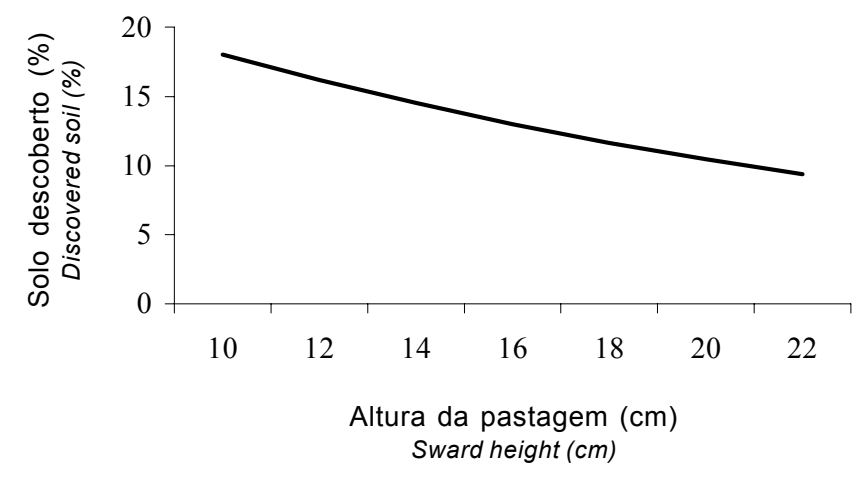

Figura 2 - Porcentagem de solo descoberto em pasto de aveia preta IAPAR 61 + ervilha forrageira, em função da altura de pasto $(\mathrm{cm})$ usando a técnica BOTANAL. $P<0,05 . Y=(\exp 3,427-0,0545 * A) / 1$ $+(\exp 3,427-0,0545 * A) R^{2}=0,82$

Figure 2 - Discovered soil percentage in the oat IAPAR 61+ field pea pasture, according to sward height using BOTANAL tecnique $(\mathrm{cm})$. 


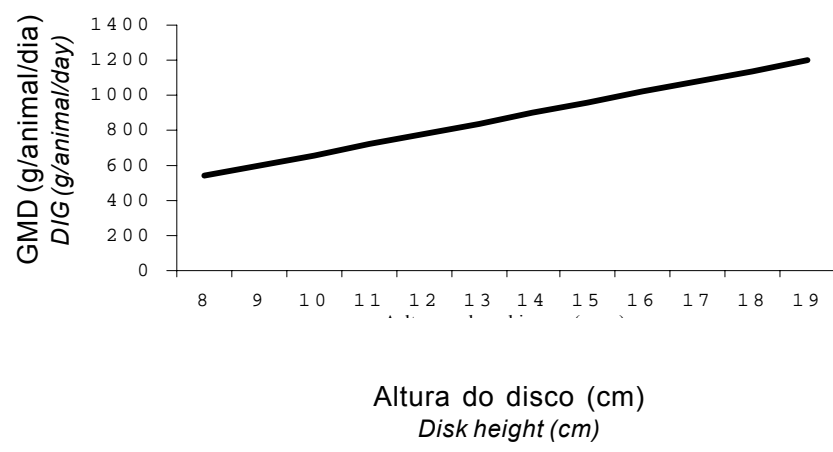

Figura 3 - Ganho médio diário (g/animal/dia) de bovinos, nelore, sob pastejo em uma mistura de aveia preta IAPAR 61 + ervilha forrageira, em função da altura do pasto usando a técnica do disco $(\mathrm{cm}) . \mathrm{Y}=64,25+59,61^{\star}$ Altura $\mathrm{P}<0,05$ $\mathrm{R}^{2}=0,67$

Figure 3 - Daily average gain (g/animal/day) of cattle, under grazing, in a misture of Oat IAPAR 61 + Field pea, according to sward eight, using disk tecnique $(\mathrm{cm})$.

observa na Figura 3. Em todas as alturas, observaram-se valores elevados de GMD e podem ser considerados muito bons, visto que estes ganhos foram superiores à realidade da região sob condição de pastagem em degradação, e baixa produção de forrageiras hibernais.

A relação linear encontrada para GMD em relação às alturas do pasto é discordante da relação assintótica proposta por Willoughby (1958), citado por Moraes \& Maraschin (1988). Isto provavelmente devese ao fato de os níveis de altura estudados situarem-se na região inicial da curva, onde a relação tende a ser linear, e provavelmente não se atingiu o ponto crítico que representa o mínimo de forragem disponível que pode sustentar o máximo consumo e desempenho animal. Segundo Canto et al. (1997), a utilização de leguminosas no pasto ocasionaria um aumento no GMD, porém, para o caso deste experimento, a porção reduzida da ervilha forrageira na composição botânica da mistura não condicionou alta participação da leguminosa na dieta consumida pelos novilhos em pastejo. Resultados semelhantes em GMD observados nesta pesquisa foram semelhantes aos constatados por Quadros \& Maraschim (1987) e Lustosa (1998) e podem ser atribuídos, em parte, à boa qualidade da forragem consumidas por eles, em termos de PB e DIVMS, mesmo numa condição subtropical.
Os valores estimados de ganho de peso vivo por hectare (GPV/ha) são apresentados na Tabela 1. O GPV/ha oscilou de $127 \mathrm{~kg} / \mathrm{ha}$ a $8,9 \mathrm{~cm}$ para $356 \mathrm{~kg} /$ ha a $18,3 \mathrm{~cm}$, porém não ocorreu diferença significativa $\left(\mathrm{P}^{3} 0,05\right)$ nas diferentes alturas avaliadas. Estes rendimentos são semelhantes aos encontrados no trabalho de Coelho et al. (1994) para aveia preta + azevém + trevo vesiculoso, porém diferentes daqueles encontrados por Quadros \& Maraschin (1987) e Roso \& Restle (1998), uma vez que estes últimos trabalharam em condições mais propícias de temperatura e precipitação pluviométrica.

Os dados de GPV/ha superaram os obtidos por Lustosa (1998), que trabalhou em condições de integração lavoura e pecuária que, no primeiro ano, obteve ganhos em torno de $150 \mathrm{~kg} / \mathrm{ha}$; e, no segundo ano de rotação agricultura, no verão, e pecuária, no inverno, os ganhos já foram de 403 a $700 \mathrm{~kg} / \mathrm{ha}$. Parte dos resultados observados nas alturas de pastagem de 18,3 e 10,0 cm, onde foram quantificados GPV de 256 e $211 \mathrm{~kg}$ de peso vivo/ha, respectivamente, deveu-se à localização destas unidades experimentais na região mais baixa do relevo, privilegiada em termos de nutrientes e acúmulo de água no solo. Deve ser ressaltado, com base nos dados de GPV por unidade de área aqui constatados, que a semeadura direta de espécies de estação fria se constitui em uma alternativa para aumentar os rendimentos na produção de bovinos na região noroeste do Paraná, inserida em um contexto de integração lavoura-pecuária. Os valores do número de animais.dia observados nesta pesquisa foram inferiores aos relatados por Quadros et al. (1994) e Canto et al. (1997).

Os GPV/ha podem ser considerados bons quando se leva em consideração que este é um período crítico de produção de forragem e, conseqüentemente, os rebanhos da região sob tais circunstâncias, têm rendimento mínimo e até perdem peso. Segundo Lustosa (1998), os ganhos no Paraná ficam em torno dos 90 $\mathrm{kg} / \mathrm{ha} / \mathrm{ano}$, monstrando que está havendo perdas na produção animal a pasto, haja vista que para as condições deste experimento obteve-se ganhos médios de $199 \mathrm{~kg} / \mathrm{ha}$, apenas no período crítico de inverno (60 dias de pastejo).

A lotação variou de 184 animais.dia/ha na altura de $14,7 \mathrm{~cm}$ a 424 animais.dia/ha na altura de $10,0 \mathrm{~cm}$ (Tabela 1). Não houve efeito significativo ( $\mathrm{P} \geq 0,05)$ das diferentes alturas para o número de animais.dia/ha. A lotação do pasto, medida pelo número de animais.dia/ha no presente trabalho, foi superior àquela obtida por

R. Bras. Zootec., v.31, n.3, p.1085-1091, 2002 
Tabela 1 - Altura do pasto dada pelo disco, ganho de peso vivo por hectare e lotação de um pasto consorciada de aveia preta (Avena strigosa Schreb cv. IAPAR 61) e ervilha forrageira (Pisum arvense L.)

Table 1 - Disk meter height, live weight gain per hectare, animals.day per hectare, in a mixture of black oat (Avena strigosa Schreb cv. IAPAR 61) + field pea (Pisum arvense L.)

\begin{tabular}{ccc}
\hline $\begin{array}{c}\text { Altura real do pasto }(\mathrm{cm}) \\
\text { Sward height }(\mathrm{cm})\end{array}$ & $\begin{array}{c}\text { Ganho peso vivo/ha }(\mathrm{kg} / \mathrm{ha} \mathrm{de} \mathrm{PV}) \\
\text { Liveweight gain/ha }(\text { LWG/ha })\end{array}$ & $\begin{array}{c}\text { Animais.dia/ha } \\
\text { Animals.day/ha }\end{array}$ \\
\hline 8,92 & 127 & 255 \\
10,02 & 211 & 424 \\
11,27 & 183 & 372 \\
11,88 & 205 & 289 \\
13,37 & 213 & 223 \\
13,61 & 159 & 245 \\
14,66 & 139 & 184 \\
18,27 & 356 & 350 \\
Média & & 292,5 \\
Average & 199,1 & 29,8 \\
CV $(\%)$ & 28,6 & \\
\hline
\end{tabular}

$(\mathrm{P} \geq 0,05)$.

Canto et al. (1997), 166 e 227 animais.dia/ha, numa mistura de aveia preta + ervilhaca e aveia + azevém + ervilhaca, respectivamente. A superioridade do número de animais.dia/ha registrada pela maioria dos trabalhos aqui relatados, em relação aos resultados deste, está relacionada àquelas condições serem mais propícias, principalmente, em relação à temperatura e à umidade, refletindo-se em maior produção de forragem e, conseqüentemente, em produção animal e em carga animal por área.

A preferência pelo consumo da aveia ou da ervilha forrageira foi medida em termos de percentagem. Com relação à porcentagem de consumo avaliada durante o tempo de permanência dos animais no pasto, o total de 80 plantas de ervilha forrageira marcadas passaram de plantas verdes à senescente sem que nenhum de seus folíolos tenham sido pastejados $(100 \%$ das plantas não foram pastejadas), enquanto os perfilhos de aveia eram consumidos ad libitum (100\% das plantas foram pastejadas). Talvez em condições de restrição de disponibilidade de forragem em quantidade e qualidade, os animais tivessem consumido a ervilha, porém para efeito deste experimento, quando tinham à disposição a aveia, uma forrageira de qualidade elevada e em quantidade, os animais não consumiram a ervilha forrageira.

A participação dos componentes da composição botânica da mistura, expressa em porcentagem (\%), a aveia preta IAPAR 61 representou, em média, $99,69 \%$ da mistura e a ervilha forrageira apenas
$0,31 \%$, sendo que aquela foi dominante durante todo o período experimental. A ervilha forrageira teve sua contribuição reduzida com o passar do tempo experimental, mostrando a necessidade de mais estudos para avaliar o potencial de utilização ou não, desta leguminosa consorciada com aveia.

\section{Conclusões}

A participação quase inexistente da ervilha no consórcio e o não consumo desta pelos animais em pastejo, são variáveis que requerem maiores avaliações e estudos. A ervilha forrageira desapareceu após 11 dias de pastejo, e não foi consumida pelos animais.

O potencial da mistura de aveia preta IAPAR 61 (Avena strigosa Schereb cv. IAPAR 61) e ervilha forrageira (Pisum arvense L.), pode ser evidenciado como alternativa para o período de escassez de forragem na região Norte e Noroeste do Paraná, pela manutenção de bons níveis de resíduo, mesmo nas alturas mais baixas de pastejo.

A altura do pasto é um método eficiente para o manejo do pasto, já que é parâmetro adequado para estimar resíduos de MS, tendo o disco medidor se mostrado bastante útil e eficiente para os ajustes de carga animal.

As alturas, em torno, de $18 \mathrm{~cm}$ são as mais adequadas para o manejo da aveia preta IAPAR 61, pois proporcionaram os maiores GMD, maiores resíduos de MS, valores bons de GPV/ha, alta lotação e menores áreas de solo descoberto. 


\section{Literatura Citada}

BORTOLO, M. Avaliação de pasto de coastcross-1 (Cynodon dactylon (L.) Pers.) em níveis de matéria seca sob pastejo. Maringá: Universidade Estadual de Maringá, 1999. 75p. Dissertação (Mestrado em Zootecnia) - Universidade Estadual de Maringá, 1999.

BRANSBY, D.I.; MATCHES, A.G.; KRAUSE, G.G. Disk meter for rapid estimation of herbage yield in grazing trials. Agronomy Journal, v.69, p.393-396, 1977.

CANTO, M.W. Produção de cordeiros em pasto de azevém (Lolium multiflorum Lam) + trevo branco (Trifolium repens $L$.) submetida à níveis de resíduos de forragem. Santa Maria: Universidade Federal de Santa Maria, 1994. 181p. Dissertação (Mestrado em Zootecnia) - Universidade Federal de Santa Maria, 1994.

CANTO, M.W.; RESTLE, J.; QUADROS, F.L.F. et al. Produção animal em pastos de aveia (Avena strigosa Schreb) adubada com nitrogênio ou em mistura com ervilhaca (Vicia sativa L.). Revista Brasileira de Zootecnia, v.26, n.2, p.396-402, 1997.

COELHO F.R.C.; QUADROS, F.L.F.; BARCELOS, F.A. et al. Produção animal em misturas de estação fria, sobressemeadas em um pasto natural. In: REUNIÃO ANUAL DA SOCIEDADE BRASILEIRA DE ZOOTECNIA, 31., 1994, Maringá. Anais... Maringá: Sociedade Brasileira de Zootecnia, 1994. p.293.

CORRÊA, A.R. Forrageiras: aptidão climática do Estado do Paraná. In: Comissão Paranaense de Avaliação de Forrageiras - CPAF. Forragicultura no Paraná. Londrina: 1996. p.75-92.

COSTA, J.M.V.; GARDNER, A.L. Sistema botanal - 2, (Manual do usuário). Brasília: Empresa Brasileira de Pesquisa e Agropecuária, 1984. 27p

EUCLYDES, R.F. Manual de utilização do programa SAEG (Sistema de Análise Estatística e Genéticas). Viçosa, MG: Universidade Federal de Viçosa, 1983.

GARDNER, A.L. Medição de atributos dos pastos em experimentos de pastejo. Brasília: Empresa Brasileira de Pesquisa e Agropecuária, 1968. p.113-140.

LESAMA, M.F. Produção animal em gramíneas de estação fria com fertilização nitrogenada ou associadas com leguminosas, com ou sem fertilização nitrogenada. Santa Maria: Universidade Federal de Santa Maria, 1997. 147p. Dissertação (Mestrado em Zootecnia) - Universidade Federal de Santa Maria, 1997.

LUSTOSA, S.B.C. Efeito do pastejo nas propriedades químicas do solo e no rendimento de soja e milho em rotação com pasto consorciada de inverno no sistema de plantio direto. Curitiba: Universidade Federal do Paraná, 1998. 84p. Dissertação (Mestrado em Agronomia - Ciência do Solo) Universidade Federal do Paraná, 1998.

MORAES, A.; MARASCHIN, G.E. Pressões de pastejo e produção animal em milheto cv. comum. Pesquisa Agropecuária Brasileira, v.23, n.2, p.197-205, 1988.
MORAES, A. Produtividade animal e dinâmica de um pasto de pangola (Digitaria decumbens Stent) azevém (Lolium multiflorum Lam) e trevo branco (Trifolium respens). L.), submetidas a diferentes pressões de pastejo. Porto Alegre: Universidade Federal do Rio Grande do Sul, 1991. 200p. Tese (Doutorado em Zootecnia) - Universidade Federal do Rio Grande do Sul, 1991.

MOTT, G.O.; LUCAS, H.L. The design, conduct and interpretation of grazing trials on cultivated and improved pastures. In: INTERNATIONAL GRASSLAND CONGRESS, 1952, Pensylvania. Proceedings... Pensylvania: State College Press, 1952. p.1380-1385.

PENNING, P.D.; PARSONS, A.J.; ORR, R.J. et al. Intake and behavior, responses by sheep to changes in sward characteristics under continuous stocking. Grass and Forage Science, v.46, p.15-28, 1991.

PETERSEN, R.G.; LUCAS, H.L. Experimental errors in grazingtrials. In: INTERNATIONAL GRASSLAND CONGRESS, 1960, Oxford. Proceedings... Oxford: Alden Press, 1968. p.1380-1385.

QUADROS, F.L.F.; MARASCHIN, G.E. Desempenho animal em misturas de espécies forrageiras de estação fria. Pesquisa Agropecuária Brasileira, v.22, n.5, p.535-541, 1987.

QUADROS, F.L.F.; COELHO, F.R.C., BARCELOS, F.A. et al. Avaliação de misturas de estação fria, sobressemeadas em um pasto natural e submetidas ao pastejo de bovinos - I Produção de forragem. In: REUNIÃO ANUAL DA SOCIEDADE BRASILEIRA DE ZOOTECNIA, 31., 1994, Maringá Anais... Maringá. Sociedade Brasileira de Zootecnia, 1994. p. 273 .

RESTLE, J., LUPATINI, G.C.; VALENTE, A.V. et al. Avaliação da mistura de aveia preta (Avena strigosa) e azevém (Lolium multiflorum Lam) sob pastejo submetida a níveis de nitrogênio. I. Produção animal. In: REUNIÃO ANUAL DA SOCIEDADE BRASILEIRA DE ZOOTECNICA, 30., 1993, Rio de Janeiro. Anais... Rio de Janeiro: Sociedade Brasileira de Zootecnia, 1993. p.71

ROSO, C.; RESTLE, J. Produtividade animal em pasto cultivado com gramíneas anuais de estação fria. In: REUNIÃO ANUAL DA SOCIEDADE BRASILEIRA DE ZOOTECNIA, 38., 1998, Botucatu. Anais... Botucatu: Sociedade Brasileira de Zootecnia, 1998. p.468-470.

WEBBY, R.W.; PENGELLY, W.J. The use of pasture height as a predictor of feed level in North Island Hill Country. Proceedings of the New Zealand Grassland Association, n.47, p.249-253, 1986.

Recebido em: 23/03/01 Aceito em: 21/12/01 